could be shown that violations of this rule had occurred, the matter would have to be considered by Council.

Overall the members welcomed the fact that EPS was prepared to be involved, not only because of the direct value of its action but because of the support this would give to the many individual groups concerned with scientific freedom. Again it was underlined that the essential objective was to work towards an alleviation of physicists' difficulties whenever possible.

\section{The Arms Race}

The Meeting ended with a vigorous criticism by one Member of the fact that Europhysics News had not published in full the lecture on Physics and the Arms Race that F. Barnaby had given at the 4th General Conference in York. The President explained that the Executive Committee had confirmed the view of the Editorial Board of $E N$ that the summary which had appeared in EN 9 (1978) 10 was adequate to draw the attention of physicists to the lec- ture, which had been published in full in the Proceedings of the York meeting.

\section{Next Time}

It was agreed that, in future, more time should be allowed for discussion at the General Meeting. Nota bene, it would have been helpful in planning this meeting if members had responded to the appeals in Europhysics News and in a letter to all individual members from the President, for items to be placed on the agenda.

\section{Inauguration of EISCAT}

On 26 August 1981, H.M. King Carl Gustaf of Sweden inaugurated the installations of the European Incoherent SCATter project from the receiving centre at Kiruna in the north of Sweden. Telephone links with the two other stations at Tromsø in Norway and Sodankylä in Finland meant that all three countries could participate in the ceremony and, rising to the occasion, the UHF transmitter at Troms $\emptyset$ began emissions that were successfully picked up by all stations.

EISCAT is the result of a cooperative effort between research councils in these three nordic countries plus France, the Federal Republic of Germany and the UK. Its primary objective is a study, in three dimensions, of the upper atmosphere at high latitudes by analyzing the scatter from pulsed transmissions in the $32 \mathrm{~cm}$ band. Correlation between the signals with a precision of about $1 \mu \mathrm{s}$ is made on the basis of absolute time as measured by caesium clocks located at the receiving stations. (These are periodically checked against each other by transporting a clock from one station to another!) Signals are transformed into digital records and those from Norway and Finland are then relayed to Kiruna where they are collated and reduced, following which copies are made and sent to the participants. Approximately $50 \%$ of the operating time is reserved for experiments falling within the common programme and the rest is used for special programmes of the participants, allocated in proportion to their contributions: $25 \%$ $\mathrm{D}, \mathrm{F}$ and the UK, $10 \% \mathrm{~N}$ and $\mathrm{S}$ and $5 \% \mathrm{SF}$. Still to be worked out are the working terms for scientists and technicians coming from a country other than the one in which the station is located, as at present, this is still causing difficulties.

EISCAT has not come into operation easily and the Chairman of the Council, Sir

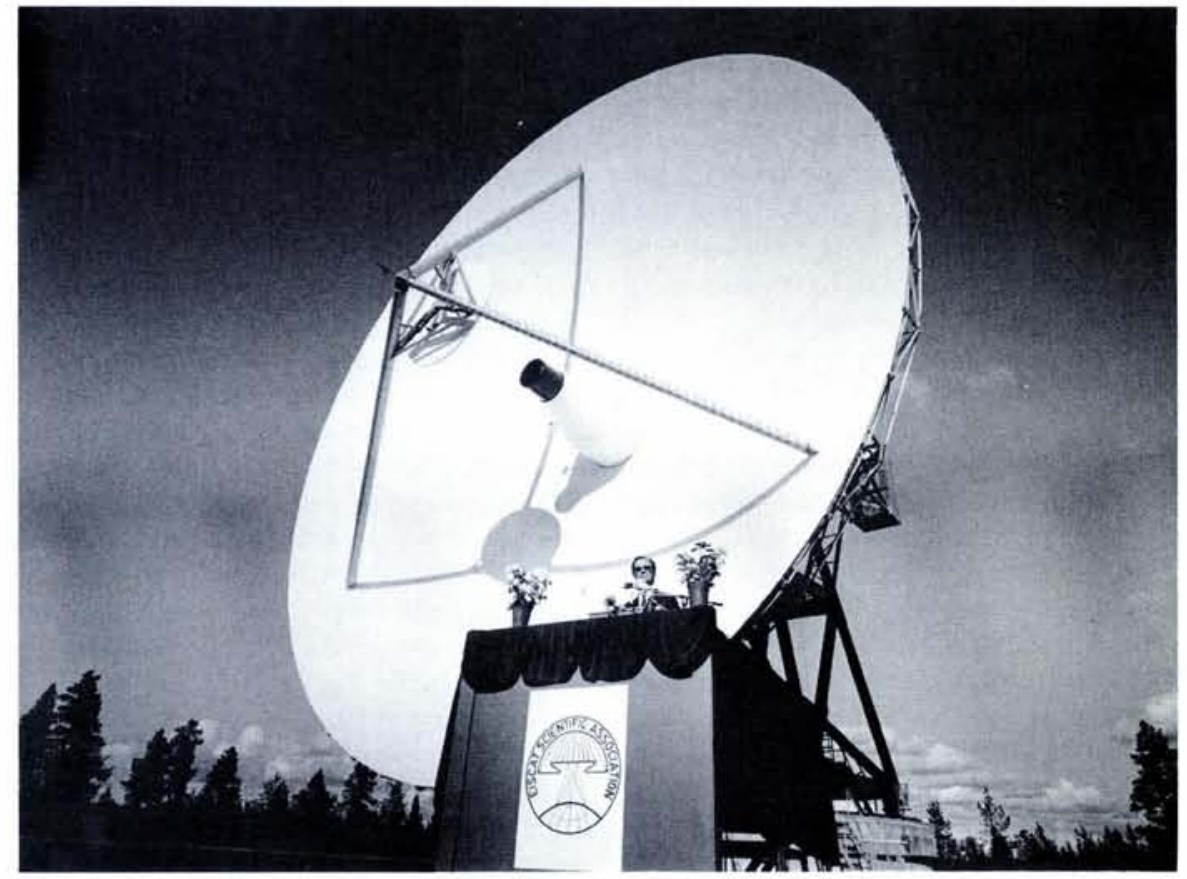

The King of Sweden inaugurates EISCAT from Kiruna with, as background, the $32 \mathrm{~m}$ receiver dish.

Granville Benyon dryly remarked in his introductory speech at the inauguration that one solar cycle had been completed between the initial moves at Ottawa in 1969 and the present day. The EISCAT agreement was eventually signed in 1975 having lain dormant between 1971 when the feasibility study was completed and the autumn of 1973. The agreement provided for a three year construction period followed by 10 years operation, but technical problems, largely connected with the UHF power source have seriously delayed the start up.

In addition to the $2 \mathrm{MW}$ UHF transmitter/receiver at Troms $ø$ there is a $6 \mathrm{MW}$ VHF radar system, but receivers for the UHF signals only are installed at Kiruna and Sodankylä. Each comprises a $32 \mathrm{~m}$ fully steerable dish reflecting into a $5 \mathrm{~m}$ secondary reflector and from there into a helium cooled collector operating at $20 \mathrm{~K}$. The VHF radar operating on a wavelength of $1.34 \mathrm{~m}$ comprises a $120 \mathrm{~m}$ parabolic trough, $40 \mathrm{~m}$ wide containing 128 pairs of dipoles along the focal line. The trough is divided into four sections the elevation of which can be independently set. Although physically fixed along the magnetic meri- dian, by adjusting the dipoles and phasing the signals, the direction can be swung in azimuth $\pm 20^{\circ}$.

The first experiment in the common programme will have the UHF transmitter pointing up along the magnetic field, while the remote sites focus on one area in the $F$ region (over $150 \mathrm{~km}$ ) and six heights in the E region (100-150 km altitude). From the measurements made it will be possible to determine electron density, neutral density and plasma motion. A second experiment is designed to map ionization intensities at fixed altitudes and latitudes in the auroral zone and their evolution with time, the transmitter on this occasion scanning on a $\mathrm{N}-\mathrm{S}$ line. Third experiment is designed to scan three different locations in the $\mathrm{F}$ and $\mathrm{E}$ regions and correlate the signals with ground-based measurements.

EISCAT will also be collaborating with the other incoherent scatter laboratories in the world but its own facilities are sufficiently unique with the three stations working together that it will have its hands full exploiting the wide range of experimental possibilities that are now opened. 